\title{
Caregivers' Sense of Coherence: Implications on Direct and Indirect Costs of Dementia Care
}

\author{
Oriol Turró-Garriga ${ }^{\mathrm{a}, \mathrm{b}, *}$, Vanesa Viñas-Díez ${ }^{\mathrm{c}}$, Josep Lluís Conde-Sala ${ }^{\mathrm{a}, \mathrm{c}}$, Laia Calvó-Perxas ${ }^{\mathrm{a}}$, \\ Marta Cullell-Juncàd $^{\mathrm{d}}$, Glòria Mas-Vall-llosera ${ }^{\mathrm{d}}$, Margarida Flaquée ${ }^{\text {, Antoni Turon-Estrada }}{ }^{\mathrm{b}}$, \\ Dolors Juvinyà-Canal ${ }^{\mathrm{f}}$, Eneida Mioshi ${ }^{\mathrm{g}}$ and Josep Garre-Olmo ${ }^{\mathrm{a}, \mathrm{b}, \mathrm{h}}$ \\ ${ }^{a}$ Aging, Disability and Health Research Group of Girona Biomedical Research Institute [IdIBGI], Salt, Catalonia \\ ${ }^{\mathrm{b}}$ Registry of Dementia of Girona (ReDeGi), Institut d'Assistència Sanitària, Salt, Catalonia \\ ${ }^{\mathrm{c}}$ Faculty of Psychology, University of Barcelona, Barcelona, Catalonia \\ ${ }^{\mathrm{d}}$ Centre Socio Sanitari Bernat Jaume, Fundació Salut Empordà, Figueres, Catalonia \\ ${ }^{\mathrm{e}}$ Centre Socio Sanitari Palamós Gent Gran, Serveis Sanitaris Integrats del Baix Empordà, Palamós, Catalonia \\ ${ }^{\mathrm{f}}$ Health Promotion Chair, University of Girona, Girona, Catalonia \\ ${ }^{\mathrm{g}}$ School of Health Sciences, University of East Anglia, Norwich, United Kingdom \\ ${ }^{\mathrm{h}}$ Department of Medical Sciences, University of Girona, Girona, Catalonia
}

Accepted 1 August 2020

\begin{abstract}
.
Background: Dementia care is associated with physical, emotional, and monetary impact on the informal carers providing unpaid care. Differences in the personal characteristics of caregivers may help explain the variations in the costs of dementia care.

Objective: The aim of this study was to analyze the effect of caregivers' sense of coherence (SOC) on direct and indirect costs in dementia care.

Methods: A cross-sectional study was conducted in community dwelling caregivers of patients with Alzheimer's disease. Data of healthcare services were obtained from clinical registries, and information was collected from caregivers regarding their use of social care resources and time spent caregiving. The transformation of all costs into Euros was made assigning a fixed cost of $10.29 € / \mathrm{h}$ and $16.24 € / \mathrm{h}$ for assisting in instrumental and basic activities of daily living, respectively. Caregivers' SOC was assessed using the Orientation to Life Questionnaire (OLQ-13). Adjusted regression models were developed, with different types of costs as dependent variables.

Results: A sample of 147 caregivers was recruited. The mean OLQ-13 score was 73.3 points $(\mathrm{SD}=11.6)$. The regression models showed a small association between caregivers' SOC and direct costs, mainly linked to the use of social care resources $\left(r^{2}=0.429 ; \beta=-15.6 € /\right.$ month $)$, and a greater association between SOC and indirect costs $\left(r^{2}=0.562 ; \beta=-222.3 € /\right.$ month $)$. Conclusion: Increasing caregivers' SOC could reduce dementia care costs by decreasing the use of social care resources and caregiving time.
\end{abstract}

Keywords: Alzheimer's disease, caregiver, cost of illness, dementia, direct service cost, healthcare cost, sense of coherence

${ }^{*}$ Correspondence to: Oriol Turró-Garriga, Edifici Mancomunitat 1, Parc Hospitalari Martí i Julià, Dr. Castany s $\backslash \mathrm{n} 17190$, Salt (Girona), Catalonia. Tel.: +34 972182600 (ext. 1831); E-mail: oriol.turro@ias.cat.

\section{INTRODUCTION}

Over 47 million people live with dementia worldwide according to the World Alzheimer Report 2016, with this number predicted to almost double in 
2030 [1]. The same study projected an annual socioeconomic cost associated with dementia of $\$ 507.49$ billion in 2030, but new research has recently revised this cost upwards [2].

Healthcare-associated costs increase with a person's dependence. In fact, institutionalization is one of the most expensive resources in healthcare, with greater dependence in daily activities and presence of behavioral and psychological symptoms the main causes of institutionalization in dementia [3, 4]. However, the majority of people with dementia are cared for at home in the community by their family or relatives [5]. Caregiving is a complex task as family caregivers usually encounter significant challenges, such as not living in the same house or neighborhood as their relative with dementia, having other responsibilities like looking after small children (sandwich generation caregiver), and working (paid job outside the home) $[6,7]$. Caregivers' burden is a high risk factor for early institutionalization of people with dementia and for greater use of resources [8,9].

Thus, reviewing or looking for new options in caregiving resources and caregiving systems is essential for healthcare systems to manage their budgets. A recently published review highlighted the importance of establishing a common understanding of the hidden socioeconomic impact of dementia beyond the formal healthcare system [10]. Reducing the cost of dementia care is one of the priorities of national healthcare systems in Western countries, with some researchers and academics working with the model proposed by Antonovsky (Salutogenesis). This model (antagonist of pathogenesis) describes a construct, sense of coherence (SOC), which represents a global orientation to life among those living in an 'ease-disease' continuum [11]. In Antonovsky's own words: "The sense of coherence is a global orientation that expresses the extent to which one has a pervasive, enduring though dynamic feeling of confidence that (1) the stimuli deriving from one's internal and external environments in the course of living are structured, predictable, and explicable; (2) the resources are available to one to meet the demands posed by these stimuli; and (3) these demands are challenges, worthy of investment and engagement." [12]. This 1970s theory has become increasingly used by public health organizations, with many studies translating this model into health action plans in oncology, physiotherapy, and dementia [13]. However, there are currently only a few of these studies in dementia, with the main focus being on caregivers rather than care recipients [14]. Factors such as anxiety and burden among caregivers have been analyzed and correlated with their SOC $[15,16]$. Although dementia can change the form of relations in a negative way, some caregivers express positive aspects associated with these changes [17]. These differences in perceived (expressed) burden are associated with the use of resources, including the early institutionalization of people with dementia.

Although there is no consensus on how costs should be calculated, especially unpaid costs and those associated with the emotional impact of dementia care, there is agreement on the need to shift policies from institutional settings to home- and community-based settings [18]. If a caregiver's ability to cope with the stressors associated with caring increases, this may additionally reduce the utilization of health care system resources, resulting in less caring time and/or lower levels of stress for carers. The aim of this study was to analyze the association between a caregiver's SOC and the costs associated with care, assessing the cost of using medical healthcare services and other resources (i.e., day care centers or domiciliary care services), as well as the cost of the time spent caregiving (informal cost/unpaid cost).

\section{MATERIALS AND METHODS}

\section{Design and population}

The 'Sense of Coherence and Dementia Study' (SOC \& DEM study) is a prospective observational study of family caregivers of people with Alzheimer's disease (AD) living in the community in Spain. The main purpose of the study is to assess the relevance of SOC in the personal and financial evolution of caregiving throughout 24 months. This present study was cross-sectional, using baseline data of people enrolled over 12 months from March 2018.

\section{Sample}

A convenience sample was used of 147 people with $\mathrm{AD}$ and their family caregivers attending three memory clinics in the north-east region of Catalonia (Girona): 'Centre Socio-Sanitari (CSS) La República' in Salt, 'Centre Socio-Sanitari Palamós Gent Gran' in Palamós, and 'Centre Socio-Sanitari Bernat Jaume' in Figueres. Sample size was calculated by accepting an alpha risk of 0.05 and a beta risk of 0.2 in a two-sided test, and a minimum detectable effect of 0.15 . 


\section{Inclusion and exclusion criteria}

\section{Inclusion criteria}

1) Individuals with a primary caregiver defined as a family relative who attends to and supervises the patient in their daily activities for a minimum of $4 \mathrm{~h} /$ week.

2) Individuals with a clinical diagnosis of mild to moderate AD (4-6a according to the Global Deterioration Scale and the FAST scale) [19].

\section{Exclusion criteria}

1) Individuals with expressive aphasia and/or with moderate-to-severe difficulties in comprehension that are related to AD.

2) Vision or hearing impairment, or an inability to read and write (illiteracy).

3) People looked after by different family caregivers in different homes.

4) Primary caregivers who provide care to more than one dependent.

\section{Procedure}

Specialists from the memory clinics informed patients and their caregivers about the study. Visits were scheduled by telephone, and an experienced psychologist conducted the interviews in the centers.

\section{Ethical considerations}

The SOC \& DEM study protocol was approved by the hospital's clinical ethics committee (ref v2:18/12/147). All participants consented to participate in the study.

\section{Variables and instruments}

\section{Sociodemographic variables}

A questionnaire was developed to collect information on both the patients and their caregivers. Age, gender, education level, and the patient-caregiver relationship were recorded.

\section{Variables associated with costs}

Costs were divided into direct and indirect costs. Direct costs included those associated with the use of healthcare resources and services. Information on any medical visits in the previous 6 months before the start of the study (to primary care and specialized services such as neurology, geriatrics, and neuropsychology) and visits to an emergency department and/or the number of days of hospitalization were recorded. Direct costs also included those associated with the use of public and private social care resources (mainly domiciliary care, day care centers, and participation in cognitive stimulation treatment programs). Indirect costs included those attributed to specific costs for time spent by caregivers on assisting individuals with dementia in their instrumental and basic activities of daily living (ADL). The monetary cost of using healthcare resources and visits was extracted from Vela et al., who described it as "a fee or an indirect cost applied to all healthcare activities financed by Catalan Health care system (CatSalut) during 2014, computing the health expenditure made up by each person and adding it all up for the inhabitants of Catalonia" [20]. We recorded the number of each type of visit and its specific cost. In the case of emergency visits and hospitalizations, we used only the mean cost. The cost of private services such as home caring and day care centers was also included. We used the standard costs established by CatSalut for domiciliary care $(13.83 € / \mathrm{h})$ and for part-time $(370.39 € /$ month $)$ or full-day (617.32€/month) attendances at a day care center. Finally, the cost of services such as using a private physician or complementary private health insurance was included too.

As for indirect costs, we assigned a fixed monetary cost of $10.29 € / \mathrm{h}$ for assisting with instrumental ADL (IADL) and $16.24 € / \mathrm{h}$ for assisting with basic ADL (BADL) (http://www.idescat.cat). The caregiving time was recorded as the number of hours per week spent in the last two weeks providing assistance with IADL and BADL.

\section{Demographic variables and SOC}

Data on sociodemographic variables such as sex, age, education level, household income, civil status, and kinship were recorded.

Sense of coherence (SOC): The Orientation to Life Questionnaire (OLQ-13) consists of 13 items, which include: "Have you ever been surprised in the past by the behavior of people who you thought you knew well?" or "Do you experience feelings that you would rather not have to endure?" [12]. The items are scored on a seven-point Likert scale (e.g., $1=$ never, 7 = always). Negatively-worded items are reverse coded (items 1, 2, 3, 7, 10). Higher scores indicate higher levels of SOC. The scale has shown appropriate internal consistency and high construct and cross-cultural validity [21]. The OLQ-13 has been adapted to the Spanish older population [22, 23]. 
Patient clinical variables

Information on the main sociodemographic variables such as sex, age, education level, and civil status was recorded.

Disability of the patient: This was evaluated with the Dependence Scale (DS), which has 13 items, 2 of which have 3 options for response and 11 have dichotomous answers to identify the degree of dependence from the minimum (range $=0-15$ ) $[24,25]$. The DS scores are used to indicate the level of dependence ranging from 0 (no dependence) to 5 (complete dependence) [26].

Cognitive status: This was assessed with the MiniMental State Examination (MMSE) questionnaire, with scores ranging from 0 to 30 (the lower the score, the greater the cognitive impairment) [27].

Behavioral and psychological symptoms in dementia (BPSD): The presence of BPSD was evaluated with the Neuropsychiatric Inventory - Questionnaire (NPI-Q) [28]. The NPI-Q is a self-administered questionnaire completed by the caregiver. Each of the 12 NPI-Q domains contains a question that reflects the cardinal symptoms of that particular domain. The NPI-Q indicates symptom severity and distress levels for each symptom reported, with the total severity and distress scores reflecting the sum of the individual domain scores. A higher score means more symptoms and distress (range $=0-96$ ).

\section{Statistical analysis}

A descriptive analysis was performed for the clinical and sociodemographic characteristics. Absolute and relative frequencies were used for the qualitative variables, while central tendency and dispersion measures were used for the quantitative variables. Parametric and non-parametric tests were used for quantitative variables, while chi-squared test was used for categorical variables. Bivariate analyses were conducted to compare the measures of cost by categorical variables. Correlation analyses were performed for the OLQ-13 score and cost variables, taking into account the minimum sample size for a moderate effect size of 0.3 ( 89 people). The classification of the correlation effect was according to Cohen's criteria ( 0.1 , low; 0.3 , moderate; and $\geq 0.5$, high).

The direct cost was divided into healthcare costs (the cost of using all services in the previous 6 months) and the costs of using social care resources (during the month of the baseline visit). A linear model was used, with each cost as the dependent variable and the caregiver variables as the
Table 1

Description of the sample

\begin{tabular}{lc}
\hline & Mean $(\mathrm{SD}) / \mathrm{N}(\%)$ \\
\hline Patients & \\
Age & $78.4(5.9)$ \\
Gender - woman & $92(62.6)$ \\
Civil status - widow & $41(27.9)$ \\
MMSE & $19.4(11.6)$ \\
NPI-Q & $4.0(3.7)$ \\
Caregivers & \\
Age & $65.0(12.9)$ \\
Gender - female & $90(61.2)$ \\
Relationship - spouse & $81(55.1)$ \\
Cohabitation - yes & $99(67.3)$ \\
Education level - primary school or less & $81(55.1)$ \\
Household income $\rightarrow$ 25,000 $€ / y e a r ~$ & $43(29.5)$ \\
\hline
\end{tabular}

independent variables. The analysis of tolerance and collinearity was used to adjust the model. Variables such as the DS and NPI-Q scores were also included. The indirect cost (caregiving time) was analyzed by comparing users of resources and non-users.

All statistical comparisons were bilateral, and confidence intervals were calculated using a $95 \%$ reliability level. Data processing and analysis were performed using IBM SPSS v. 21 for Windows.

\section{RESULTS}

\section{Description of the sample}

The study sample consisted of 294 participants, of whom 147 were caregivers and 147 were care recipients. The percentage of women was higher in both groups. Spouses represented $55.1 \%$ of the caregivers, while the remaining caregivers were sons/daughters (except in eight cases, where the caregiver was a different type of family member). Three-quarters of the caregivers cohabited with the care recipient, while only $18 \%$ of the non-partner caregivers cohabited with the care recipient. Among our study participants, $91.2 \%$ of the individuals with dementia continued to live at their own home, of whom $76.6 \%$ were classified as having a level $1(36.3 \%)$ or level $2(40.3 \%)$ of dependence according to the DS score. A full description of the characteristics of the sample is shown in Table 1.

The mean total OLQ-13 score was 73.3 points $(\mathrm{SD}=11.6)$. There were no differences in SOC according to the caregivers' gender, education level, kinship or cohabitation with the person with dementia, nor between the users and non-users of social care resources (73.7 versus 72.9; Mann-Whitney $\mathrm{U}=2,502.0 ; p=0.754)$. However, there was a 
Table 2

Costs of the health and social care resources and of the caregiving time

\begin{tabular}{lcc}
\hline & $\mathrm{N}(\%)$ & $\begin{array}{c}\text { Mean } € / \\
\text { person }(\mathrm{SD})\end{array}$ \\
\hline Primary care & $103(70.1)$ & $€ 138.7(102.2)$ \\
Specialists & $147(100)$ & $€ 175.6(105.6)$ \\
Emergencies* & $28(19.1)$ & $€ 106.4(\mathrm{na})$ \\
Hospitalization* & $10(6.8)$ & $€ 2,067.7(\mathrm{na})$ \\
Social care resources, €/month & $58(25.3)$ & $€ 336.7(302.1)$ \\
$\mathrm{SAD}, € /$ month & $22(15.0)$ & $€ 322.5(355.8)$ \\
DC, $€ /$ month & $21(14.9)$ & $€ 403.8(179.1)$ \\
Other, $€ /$ month & $27(18.5)$ & $€ 164.4(258.7)$ \\
Caregiving time, $€ /$ month & $147(100)$ & $€ 842.8(758.6)$ \\
BADL, $€ /$ month & $70(47.6)$ & $€ 420.5(391.6)$ \\
IADL, €/month & $147(100)$ & $€ 642.5(512.3)$ \\
\hline
\end{tabular}

*Costs are an approximation extracted from Vela et al., 2019 [20]. $\mathrm{SAD}$, domiciliary care; DC, day care center; BADL, basic activities of daily living; IADL, instrumental activities of daily living.

significant difference in the relationship between SOC and the use of resources by gender, with SOC being higher in male and lower in female users (76.9 versus 71.2; Mann-Whitney $\mathrm{U}=260.0 ; p=0.016$ ).

Primary care was the most used healthcare service. Over $70.1 \%$ of the sample had visited their primary care center in the previous 6 months on an average of 1.8 occasions $(\mathrm{SD}=1.9$; median $=1)$. Of note, all the patients had attended memory clinics in that period, with specialist appointments generally comprising a visit to a neurologist $(91.8 \%$ of the participants) that involved an additional neuropsychological assessment in $63.3 \%$ of the appointments. Almost all the diagnoses had been made with neuroimaging, mainly computed tomography (62.6\%) and MRI (36.1\%), while 58.5\% had laboratory tests conducted such as the analyses of complete serum biochemistry and vitamin B12 levels.

Only 10 individuals with dementia had been an inpatient in the previous 6 months, while 27 (18.5\%) had attended the emergency department once (or more often). Domiciliary care and day care centers were used by $22(15 \%)$ and 21 (17 part-time and 4 daily) participants, respectively. Finally, 27 individuals with dementia used other types of healthcare resources such as cognitive stimulation therapy and assistive technology (e.g., telecare alarm).

Caregivers reported providing less than half an hour a day $($ mean $=0.4 ; \mathrm{SD}=0.7)$ of support for BADL and more than 2 hours a day (mean $=2.1$; $\mathrm{SD}=1.7$ ) of support for IADL. Table 2 shows the costs associated with these different services and assistance, while Fig. 1 shows the distribution of these costs.

\section{Caring cost distribution}

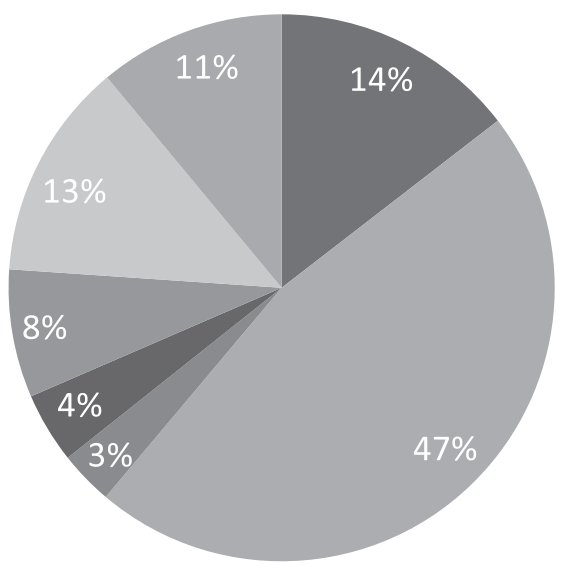

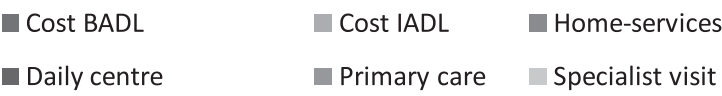

Complementary tests

Fig. 1. Care cost distribution, including the costs associated with healthcare services, social care resources, and time spent assisting care recipients in their ADL.

\section{Differences in direct and indirect costs according to the characteristics of the caregiver}

When analyzing the three types of costs, namely those associated with healthcare services, social care resources, and caregiving time, we observed differences that correlated with the characteristics of the care recipients and caregivers. Only adult child cohabitating caregivers showed a small statistically significant relationship ( $€ 108.1$ versus $€ 80.2$; Mann-Whitney $\mathrm{U}=757.5 ; p=0.016$ ).

Significant differences were found in the cost of using social care resources (mainly domiciliary care and day centers) in relation to the characteristics of the caregivers. Kinship (adult child versus spouse) ( $€ 178.0$ versus $€ 96.1 ; p=0.012$; Cohen's $d=0.39)$ and no cohabitation ( $€ 184.1$ versus $€ 108.0$; $p=0.012$; Cohen's $d=0.25$ ) were the main factors associated with a greater use of domiciliary care. The civil status (widow) and greater dependence of the care recipient correlated with day care center use (rho $=0.271 ; p=0.001)$. The age of the person with dementia was associated with an increased use of domiciliary care (rho $=0.299 ; p<0.001)$, with reduced expenses in complementary tests such as neuroimaging or neuropsychological assessments $($ rho $=-0.189 ; p=0.021)$. 
The mean global cost was $16.55 € /$ day (median $=$ 13.8; $\mathrm{SD}=9.0 ;$ rank $=4.34-32.65$ ), including the costs associated with healthcare and social care services, resources like domiciliary care and/or day care centers, and caregiving time. The main factor associated with increasing caregiving time was the dependence of the person with dementia. The cost of the caregiving time correlated strongly with BADL and IADL (rho $>0.6$ in both cases).

\section{The effect of SOC on costs}

SOC showed a small correlation with healthcare service costs $($ rho $=-0.195 ; p=0.022$ ), but a larger correlation with the costs of using social care resources (rho $=-0.226 ; p=0.007$ ). In terms of direct costs, spouses showed a significant correlation (rho $=-0.295 ; p=0.007$ ), while adult children did not, and only cohabitating caregivers showed a small correlation ( $\mathrm{rho}=-0.211 ; p=0.036$ ). Thus, a higher SOC of the spouses correlated with lower medical costs (rho $=-0.321 ; p=0.004$ ), but this was not observed for adult children. Likewise, a higher SOC in cohabiting caregivers correlated with lower costs of using social care resources (rho $=-0.261$; $p=0.009$ ) and healthcare services (rho $=-0.250$; $p=0.013$ ). Sole caregivers showed a moderate correlation between SOC and the cost of using social care resources (rho $=-0.308 ; p=0.023$ ). For indirect costs, sole caregivers also showed a correlation between SOC and costs associated with caregiving time (rho $=-0.208 ; p=0.045$ ). A stronger correlation between SOC and costs were observed in caregivers who used social care resources (rho $=-0.336$; $p=0.010$ ) than in those who did not use them. Table 3 shows the results of the different linear regression models used that were adjusted for SOC, DS scores, NPI-Q scores, household income, sole caregivers, and the caregiver's education level.

\section{DISCUSSION}

This study's main objective was to assess the effect of the caregiver's SOC on the direct and indirect costs of taking care of a relative with dementia. We observed that the caregiver's SOC may reduce the costs of care. Direct and indirect costs were also affected by the dependence of the individual with $\mathrm{AD}$, the type of relationship (spouse or adult child), cohabitation with the caregiver, and being a sole caregiver. The main differences in the costs were in those
Table 3

Correlation coefficients of OLQ-13 scores in different adjusted linear regression models

\begin{tabular}{lcccc}
\hline & $\mathrm{r}^{2}$ model & $\beta$ & $\begin{array}{c}\text { Standard } \\
\text { error }\end{array}$ & $p$ \\
\hline Direct costs & & & & \\
$\quad$ - Healthcare services & 0.053 & $\mathrm{NA}$ & $\mathrm{NA}$ & $\mathrm{NA}$ \\
$\quad$ - Social care resources* & 0.429 & -15.1 & 3.2 & $<0.001$ \\
$\begin{array}{l}\text { Indirect costs } \\
\quad \text { Non-users of resources }\end{array}$ & 0.365 & 13.3 & 62.8 & 0.833 \\
$\quad$ - Users of resources* & 0.562 & -222.3 & 81.3 & 0.009 \\
\hline
\end{tabular}

* Only caregivers who used social care resources $(\mathrm{N}=61)$. Models were adjusted for sense of coherence (SOC), Dependence Scale scores, Neuropsychiatric Inventory - Questionnaire scores, household income, sole caregivers, and education level.

associated with the use of social care resources like domiciliary care or day care centers.

Dementia care is associated with increasing medical and social care costs. It also has a physical, emotional, and monetary impact on the relatives providing unpaid care. Dependence and BPSD are the main variables associated with increasing costs in $\mathrm{AD}$ care in terms of both the costs of using healthcare services and the costs associated with caregiving time $[4,29,30]$. European multinational studies have reported an average cost ranging from $€ 14,500$ to $€ 17,000$ per year in dementia patients at home with some autonomy in ADL [31,32]. This is more than double the figures obtained in another study in which the participants had mainly mild AD, like in our study, and baseline costs were $€ 535$ per month [33].

\section{Caregiver's personal characteristics associated with dementia care costs}

SOC had a significant influence on the use of social care resources, with a reduction of $€ 15$ per month in direct costs per point of increased SOC and a reduction of $€ 222.3$ in indirect costs. These results are in accordance with those of previous studies showing greater increases in costs associated with caregiving time during the course of the disease [34]. Although one SOC point may not represent a large change, it could increase in significance during the whole process of dementia. Moreover, a 3-point increase is a relevant change in SOC ( $10 \%$ improvement) that represents a greater reduction in the costs associated with using social care resources. In fact, the use of social care resources and paid carers for people with dementia is growing in Western societies. This has been linked to changes in the characteristics of caregivers, such as having a paid job, not cohabiting with the care recipient $[6,35]$, and, more specifically, 
having a high education level and good employment [36]. The use of social care resources (e.g., day care centers and paid carers) involves an increase in care costs that in general are not included in public insurances (or only partially). Our study confirmed these observations, with greater use of resources linked to non-cohabiting adult child caregivers, in contrast to spouses who used fewer healthcare and social care resources. Non-cohabitation, in addition to increasing monetary care costs, are also known to cause a greater feeling of guilt (emotional cost) in caregivers $[37,38]$.

\section{Implications of sense of coherence in dementia care costs}

In our study, the use of social care resources was not generalized, and, as usual, the largest part of the care costs was unpaid [39, 40]. Therefore, if twothirds of the global cost is not reimbursed money (Fig. 2), dementia care requires high personal and family efforts, but deserves greater compromise from society as a whole. Caregivers' SOC reduced indirect costs in users of social care resources, but not in non-users. The use of social care resources could be linked to differences in the situation of the care recipient and their caregivers. The relationship between being a user of social care resources and reduced costs in relation to the SOC score could have different interpretations.

One interpretation could involve caregiver's burden. Previous research has linked burden to a lower SOC in caregivers [41, 42]. Our results indicated that an improvement of one point in the caregiver's SOC reduced care costs up to $€ 2,600$ a year (extrapolation of monthly use of resources and the amount of caregiving time per week). Furthermore, caregivers' burden is a risk factor for greater and earlier use of social care resources and the institutionalization of the person with dementia [43, 44].

In line with Antonovsky's theory, wellbeing is associated with generalized resistance resources (GRR) and a sense of coherence [45]. This health model encourages people to reflect on stressful situations in order to make them able to understand them, think about how to face them, and identify the best way to think about how dealing with a stressor can be meaningful $[46,47]$. Thus, one plausible explanation is that a greater sense of coherence promotes better use of social care resources. The reductions in costs are not due to caregivers with a better SOC not using social care resources, but are due to the SOC in caregivers allowing them to use the resource better. At the same time, handling the situation more efficiently reinforces self-esteem and self-efficacy perceptions that increase carers' sense of coherence [48].

\section{The gender role}

In the bivariate analysis, we observed differences between men and women in the relationship between using resources and a sense of coherence. It is known that the role of caregiving has an important gender component. Thus, we observed that women with paid jobs used fewer resources than men (25/75 versus 40/60). Previous analysis of the profiles of caregivers in a similar context showed similar results. In both cases, when males were the partners of care recipients, they used more external services than female partners. In addition, maintaining a paid-job outside the home increased the use of external support services and, consequently, the cost of care. Again, women used these support services less often [49]. In fact, the role of women seems perpetuated by social pressure, the job market, and social culture [38, 50-52].

Gender did not appear as a significant factor in the adjusted regression models. However, our results did not allow us to conclude any effect of gender on dementia care costs. Previous studies have not found differences by gender, but by household or social class [53]. Maybe, we should have reported characteristics of the non-participants, such as the number of women or low-income families. Moreover, cultural differences should have been taken into account when assessing, for example, time spent caring for an individual. Some people might consider caregiving a normal part of life and a duty to their family. Perceptions like these might be seen more often in spouses than in sons/daughters and more often in women than in men [54].

\section{Limitations}

We found a significant relationship between a caregiver's sense of coherence and monetary care costs, but there were some limitations of the study that should be taken into account. The first limitation was the real clinical impact of the sense of coherence on care costs. The monetary costs assigned to the services could vary even though our results were similar to those of previously published studies from other countries [30]. A limitation of our study was that the use of social resources was not 
generalized by country or by healthcare system, with specific monetary costs being higher in other European places [55].

Second, this was a cross-sectional study that did not allow the causal effects of SOC or its influence on costs to be determined. For that reason, to clarify our results, we calculated the differences in costs for 3 SOC points. For a middle-income family in Catalonia ( $€ 13,338 /$ year), a monthly reduction of more than $€ 200$ would represent a significant change in their household costs [56]. However, this study was undertaken in a specific Mediterranean region and, as mentioned previously, there were some cultural differences that could limit the generalization of our results. Comparative studies have shown differences between different countries and regions of the EU in terms of the values associated with caregiving [54].

Finally, another limitation relates to was the time of units of caring. It could difficult to generalize the results because there are some variations in this point among studies in the literature. For that reason, we only included assistance with BADL and IADL. This means that our study might have included the minimum amount of caregiving, in contrast to other studies that have included the amount of time spent supervising care recipients or other types of caregiving, which constitute a significant proportion of caregiving $[8,36,57]$.

\section{Future lines of research}

This paper is part of the SOC \& DEM study. The aim of this study is to assess the effect of the personal characteristics of caregivers on dementia care costs, and the main hypothesis is sense of coherence has an important influence on these costs (monetary and personal costs) and may reduce them. To our knowledge, this is the first study that has translated OLQ-13 scores into monetary figures associated with the care of dependent people with $\mathrm{AD}$ in the community. Although there are some limitations to generalize these results, this work could complement previous studies on the cost of healthcare in dementia, focusing on the need to improve the sense of coherence in caregivers to reduce indirect costs. This was a crosssectional study and it will be interesting to observe these relationships and their strengths longitudinally. Social support, self-esteem, and self-efficacy are direct factors associated with this improvement [58-61]. Cultural values of caregiving or clustering caregivers by their sense of coherence could be used to enhance the effects of SOC on care costs.

\section{Conclusions}

Based on our results, we conclude that investing in caregivers could reduce care costs in dementia, especially by working on the differences between genders in caregiving. Although dementia is commonly described in a negative way (dependence, disability, and loss), some caregivers and professionals are changing this perception [62]. A greater sense of coherence could promote this change. Although it will not significantly reduce direct and indirect monetary costs, a greater sense of coherence may reduce the emotional and social costs associated with caring for people living with dementia.

\section{ACKNOWLEDGMENTS}

The project was supported by a research grant from the Carlos III Institute of Health, the Spanish Ministry of Economy and Competitiveness, awarded in the 2017 call under the Health Strategy Action 20132016, within the National Program for Research aimed at the Challenges of Society, and the National Plan for Scientific and Technical Research and Innovation 2013-2016 (reference, PI17/00029; cofunded by the European Union ERDF (European Regional Development Funds)). EM is supported by a grant from Alzheimer's Society (UK) and by the National Institute of Health Research (NIHR) Applied Research Collaboration East of England (ARC EoE) programme. The views expressed are those of the authors, and not necessarily those of the NIHR, NHS, or Department of Health and Social Care.

Authors' disclosures available online (https:// www.j-alz.com/manuscript-disclosures/20-0350r3).

\section{REFERENCES}

[1] Salthouse TA (2004) What and when of cognitive aging. Curr Dir Psychol Sci 13, 140-144.

[2] Jia J, Wei C, Chen S, Li F, Tang Y, Qin W, Zhao L, Jin H, Xu H, Wang F, Zhou A, Zuo X, Wu L, Han Y, Han Y, Huang L, Wang Q, Li D, Chu C, Shi L, Gong M, Du Y, Zhang J, Zhang J, Zhou C, Lv J, Lv Y, Xie H, Ji Y, Li F, Yu E, Luo B, Wang Y, Yang S, Qu Q, Guo Q, Liang F, Zhang J, Tan L, Shen L, Zhang K, Zhang J, Peng D, Tang M, Lv P, Fang B, Chu L, Jia L, Gauthier S (2018) The cost of Alzheimer's disease in China and re-estimation of costs worldwide. Alzheimers Dement 14, 483-491.

[3] Verbeek H, Meyer G, Leino-Kilpi H, Zabalegui A, Hallberg IR, Saks K, Soto ME, Challis D, Sauerland D, Hamers JPH (2012) A European study investigating patterns of transition from home care towards institutional dementia care: 
The protocol of a RightTimePlaceCare study. BMC Public Health 12, 68.

[4] Quentin W, Riedel-Heller SG, Luppa M, Rudolph A, König HH (2010) Cost-of-illness studies of dementia: A systematic review focusing on stage dependency of costs. Acta Psychiatr Scand 121, 243-259.

[5] Pinquart M, Sörensen S (2011) Spouses, adult children, and children-in-law as caregivers of older adults: A metaanalytic comparison. Psychol Aging 26, 1-14.

[6] Viñas-Diez V, Turró-Garriga O, Portellano-Ortiz C, Gascón-Bayarri J, Reñé-Ramírez R, Garre-Olmo J, CondeSala JL (2017) Kinship and cohabitation in relation to caregiver burden in the context of Alzheimer's disease: A 24-month longitudinal study. Int J Geriatr Psychiatry 32, e72-e82.

[7] Rattinger GB, Fauth EB, Behrens S, Sanders C, Schwartz S, Norton MC, Corcoran C, Mullins CD, Lyketsos CG, Tschanz JAT (2016) Closer caregiver and care-recipient relationships predict lower informal costs of dementia care: The Cache County Dementia Progression Study. Alzheimers Dement 12, 917-924.

[8] Turró-Garriga O, López-Pousa S, Vilalta-Franch J, Turon-Estrada A, Pericot-Nierga I, Lozano-Gallego M, Hernández-Ferràndiz $\mathrm{M}$, Soler-Cors $\mathrm{O}$, Planas-Pujol X, Monserrat-Vila S, Garre-Olmo J (2010) Annual economic cost of informal care in Alzheimer's disease. Rev Neurol 51, 201-207.

[9] Pinquart M, Sörensen S (2004) Associations of caregiver stressors and uplifts with subjective well-being and depressive mood: A meta-analytic comparison. Aging Ment Health 8, 438-449.

[10] El-Hayek YH, Wiley RE, Khoury CP, Daya RP, Ballard C, Evans AR, Karran M, Molinuevo JL, Norton M, Atri A (2019) Tip of the Iceberg: Assessing the global socioeconomic costs of Alzheimer's disease and related dementias and strategic implications for stakeholders. JAlzheimers Dis 70, 323-341.

[11] Antonovsky A (1996) The salutogenic model as a theory to guide health promotion. Health Promot Int 11, 11-18.

[12] Chaiklin H (1989) Unraveling the Mystery of Health: How People Manage Stress and Stay Well.

[13] Mittelmark MB, Sagy S, Eriksson M, Bauer GF, Pelikan JM, Lindström B, Espnes GA (2016) The handbook of salutogenesis, Springer.

[14] Ablitt A, Jones GV, Muers J (2009) Living with dementia: A systematic review of the influence of relationship factors. Aging Ment Health 13, 497-511.

[15] Lo Sterzo E, Orgeta V (2017) Illness representation and sense of coherence in dementia caregiving. J Health Psychol 22, 722-732.

[16] Calvó-Perxas L, Teresa Osuna M, Gich J, Eligio-Hernández E, Linares M, Viñas M, Casas I, Turró-Garriga O, LópezPousa S, Garre-Olmo J (2012) Clinical and demographic characteristics of the cases of dementia diagnosed in the Health District of Girona throughout the period 2007-2010: Data from the Girona Dementia Registry (ReDeGi). Rev Neurol 54, 399-406.

[17] Pérez Ortiz L, Sancho Castiello M, Spottorno Giner G, Abellán García A (2005) Las personas mayores en España. T. I: Informe 2004: Datos estadísticos estatales y por Coтиnidades Autónomas.

[18] Deb A, Thornton JD, Sambamoorthi U, Innes K (2017) Direct and indirect cost of managing Alzheimer's disease and related dementias in the United States. Expert Rev Pharmacoecon Outcomes Res 17, 189-202.
[19] Reisberg B, Ferris SH, De Leon MJ, Crook T (1982) The Global Deterioration Scale for assessment of primary degenerative dementia. Am J Psychiatry 139, 1136-1139.

[20] Vela E, Clèries M, Vella VA, Adroher C, García-Altés A (2019) Population-based analysis of the Healthcare expenditure in Catalonia (Spain): What and who consumes more resources? Gac Sanit 33, 24-31.

[21] Eriksson M, Lindstrom B (2007) Antonovsky's sense of coherence scale and its relation with quality of life: A systematic review. J Epidemiol Community Health 61, 938-944.

[22] Langius A, Björvell H (1993) Coping ability and functional status in a Swedish population sample. Scand J Caring Sci 7, 3-10.

[23] Virués-Ortega J, Martínez-Martín P, Del Barrio JL, Lozano LM; Grupo Español de Estudios Epidemiológicos sobre Envejecimiento (2007) Validación transcultural de la Escala de Sentido de Coherencia de Antonovsky (OLQ-13) en ancianos mayores de 70 años. Med Clin (Barc) 128, 486-492.

[24] Stern Y, Albert SM, Sano M, Richards M, Miller L, Folstein M, Albert M, Bylsma FW, Lafleche G (1994) Assessing patient dependence in Alzheimer's disease. J Gerontol 49, M216-M222.

[25] Garre-Olmo J, Vilalta-Franch J, Calvó-Perxas L, MonserratVila S, López-Pousa S; CoDep-AD Study Group (2015) Dependence Scale for Alzheimer's disease. J Geriatr Psychiatry Neurol 28, 117-125.

[26] Zhu CW, Bruinsma BG, Stern Y (2018) Utility of the dependence scale in dementia: Validity, meaningfulness, and health economic considerations. Alzheimers Res Ther 10, 78.

[27] Folstein MF, Folstein SE, McHugh PR (1975) "Mini-mental state". A practical method for grading the cognitive state of patients for the clinician. J Psychiatr Res 12, 189-198.

[28] Boada M, Cejudo J, Tàrraga L, López O, Kaufer D (2002) Neuropsychiatric Inventory Questionnaire (NPI-Q): Validación española de una forma abreviada del Neuropsychiatric Inventory (NPI). Neurología 17, 317-323.

[29] Vickland V, Werner J, Morris T, McDonnell G, Draper B, Low LF, Brodaty H (2011) Who pays and who benefits? How different models of shared responsibilities between formal and informal carers influence projections of costs of dementia management. BMC Public Health 11, 793.

[30] Costa N, Wübker A, De Mauléon A, Zwakhalen SMG, Challis D, Leino-Kilpi H, Hallberg IR, Stephan A, Zabalegui A, Saks K, Molinier L, Wimo A, Vellas B, Sauerland D, Binot I, Soto ME, Meyer G, Stephan A, Renom Guiteras A, Sauerland D, Wübker A, Bremer P, Hamers JPH, Afram B, Beerens HC, Bleijlevens MHC, Verbeek H, Zwakhalen SMG, Ruwaard D, Rahm Hallberg I, Emilsson UM, Karlsson S, Challis D, Sutcliffe C, Jolley D, Tucker S, Bowns I, Roe B, Burns A, Leino-Kilpi H, Koskenniemi J, Suhonen R, Viitanen M, Arve S, Stolt M, Hupli M, Saks K, Tiit EM, Leibur J, Raamat K, Armolik A, Marjatta Toivari TT, Zabalegui A, Navarro M, Cabrera E, Risco E, Soto M, Milhet A, Sourdet S, Gillette S, Vellas B (2018) Costs of care of agitation associated with dementia in 8 european countries: Results from the RightTimePlaceCare study. J Am Med Dir Assoc 19, 95.e1-95.e10.

[31] Gustavsson A, Brinck P, Bergvall N, Kolasa K, Wimo A, Winblad B, Jönsson L (2011) Predictors of costs of care in Alzheimer's disease: A multinational sample of 1222 patients. Alzheimers Dement 7, 318-327.

[32] Handels RLH, Sköldunger A, Bieber A, Edwards RT, Gonçalves-Pereira M, Hopper L, Irving K, Jelley $\mathrm{H}$, 
Kerpershoek L, Marques MJ, Meyer G, Michelet M, Portolani E, Røsvik J, Selbaek G, Stephan A, De Vugt M, Wolfs C, Woods B, Zanetti O, Verhey F, Wimo A (2018) Quality of life, care resource use, and costs of dementia in 8 european countries in a cross-sectional cohort of the actifcare study. J Alzheimers Dis 66, 1027-1040.

[33] Vossius C, Rongve A, Testad I, Wimo A, Aarsland D (2014) The use and costs of formal care in newly diagnosed dementia: A three-year prospective follow-up study. Am J Geriatr Psychiatry 22, 381-388.

[34] Wimo A, Guerchet M, Ali GC, Wu YT, Prina AM, Winblad B, Jönsson L, Liu Z, Prince M (2017) The worldwide costs of dementia 2015 and comparisons with 2010. Alzheimers Dement 13, 1-7.

[35] Conde-Sala JL, Turró-Garriga O, Calvó-Perxas L, VilaltaFranch J, Lopez-Pousa S, Garre-Olmo J (2014) Three-year trajectories of caregiver burden in Alzheimer's disease. $J$ Alzheimers Dis 42, 623-633.

[36] Ruiz-Adame Reina M, Correa M, Burton K (2019) The opportunity costs of caring for people with dementia in Southern Spain. Gac Sanit 33, 17-23.

[37] Turró-Garriga O, Soler-Cors O, Garre-Olmo J, LópezPousa S, Vilalta-Franch J, Monserrat-Vila S (2008) Factorial distribution of the burden on caregivers of patients with Alzheimer's disease. Rev Neurol 46, 582-588.

[38] Conde-Sala JL, Garre-Olmo J, Turró-Garriga O, VilaltaFranch J, López-Pousa S (2010) Differential features of burden between spouse and adult-child caregivers of patients with Alzheimer's disease: An exploratory comparative design. Int J Nurs Stud 47, 1262-1273.

[39] Alzheimer's Association (2019) 2019 Alzheimer's disease facts and figures. Alzheimers Dement 15, 321-387.

[40] Alzheimer's Association (2018) 2018 Alzheimer's disease facts and figures. Alzheimers Dement 14, 367-429

[41] Shiba K, Kondo N, Kondo K (2016) Informal and formal social support and caregiver burden: The AGES Caregiver Survey. J Epidemiol 26, 622-628.

[42] Stensletten K, Bruvik F, Espehaug B, Drageset J (2016) Burden of care, social support, and sense of coherence in elderly caregivers living with individuals with symptoms of dementia. Dementia (London) 15, 1422-1435.

[43] Phillipson L, Magee C, Jones SC (2013) Why carers of people with dementia do not utilise out-of-home respite services. Health Soc Care Community 21, 411-422.

[44] Bangerter LR, Griffin JM, Zarit SH, Havyer R (2019) Measuring the needs of family caregivers of people with dementia: An assessment of current methodological strategies and key recommendations. J Appl Gerontol 38, 1304-1318.

[45] Antonovsky A (2012) Unraveling the mystery of health: How people manage stress and stay well. The Health Psychology Reader, pp. 127-139.

[46] Super S, Wagemakers MAE, Picavet HSJ, Verkooijen KT, Koelen MA (2016) Strengthening sense of coherence: Opportunities for theory building in health promotion. Health Promot Int 31, 869-878.

[47] Tan KK, Chan SWC, Wang W, Vehviläinen-Julkunen K (2016) A salutogenic program to enhance sense of coherence and quality of life for older people in the community: A feasibility randomized controlled trial and process evaluation. Patient Educ Couns 99, 108-116.
[48] Turró-Garriga O, Conde-Sala JL, Viñas V, Turon-Estrada A, Cullell-Juncà $\mathrm{M}$, Calvó-Perxas L, Juvinyà-Canal D, Mioshi E, Garre-Olmo J (2019) Antonovsky's sense of coherence and resistance resources reduce perception of burden in family carers of people with Alzheimer's disease. Aging Ment Health, doi: 10.1080/13607863.2019.1667297

[49] Ruiz-Adame Reina M, González-Camacho MC, RomeroGarcía JE, Sánchez-Reyes Fernández LM (2017) Profiles of Alzheimer's caregivers in Spain: Social, educational and laboral characteristics. Scand J Caring Sci 31, 867-877.

[50] Van der Lee J, Bakker TJEM, Duivenvoorden HJ, Dröes RM (2014) Multivariate models of subjective caregiver burden in dementia: A systematic review. Ageing Res Rev 15, 76-93.

[51] Pillemer S, Davis J, Tremont G (2018) Gender effects on components of burden and depression among dementia caregivers. Aging Ment Health 22, 1156-1161.

[52] Mayston R, Lloyd-Sherlock P, Gallardo S, Wang H, Huang Y, Montes de Oca V, Ezeah P, Guerra M, Sosa AL, Liu Z, Uwakwe R, Guerchet MM, Prince M (2017) A journey without maps-understanding the costs of caring for dependent older people in Nigeria, China, Mexico and Peru. PLoS One 12, $\mathrm{e} 0182360$.

[53] Lundberg O, Peck MN (1994) Sense of coherence, social structure and health: Evidence from a population survey in Sweden. Eur J Public Health 4, 252-257.

[54] Haberkern K, Schmid T, Szydlik M (2015) Gender differences in intergenerational care in European welfare states. Ageing Soc 35, 298-320.

[55] Landeiro F, Wace H, Ghinai I, Nye E, Mughal S, Walsh K, Roberts N, Lecomte P, Wittenberg R, Wolstenholme J, Handels R, Roncancio-Diaz E, Potashman MH, TockhornHeidenreich A, Gray AM (2018) Resource utilisation and costs in predementia and dementia: A systematic review protocol. BMJ Open 8, e019060.

[56] Idescat. Indicadors anuals. Renda mitjana neta anual de les llars. Per sexe.

[57] Rapp T, Andrieu S, Chartier F, Deberdt W, Reed C, Belger M, Vellas B (2018) Resource use and cost of Alzheimer's disease in France: 18-month results from the GERAS Observational Study. Value Health 21, 295-303.

[58] Rosell-Murphy M, Bonet-Simó JM, Baena E, Prieto G, Bellerino E, Solé F, Rubio M, Krier I, Torres P, Mimoso S (2014) Intervention to improve social and family support for caregivers of dependent patients: ICIAS study protocol. $B M C$ Fam Pract 15, 53.

[59] Thompson CA, Spilsbury K, Hall J, Birks Y, Barnes C, Adamson J (2007) Systematic review of information and support interventions for caregivers of people with dementia. BMC Geriatr 7, 18.

[60] Kim D (2017) Relationships between caregiving stress, depression, and self-esteem in family caregivers of adults with a disability. Occup Ther Int 2017, 1686143.

[61] Kishita N, Hammond L, Dietrich CM, Mioshi E (2018) Which interventions work for dementia family carers?: An updated systematic review of randomized controlled trials of carer interventions. Int Psychogeriatr 30, 1679-1696.

[62] de Vugt M, Dröes RM (2017) Social health in dementia. Towards a positive dementia discourse. Aging Ment Health 21, 1-3. 